\title{
Remembering Aram A. Yengoyan
}

\begin{abstract}
Aram A. Yengoyan had been associated with $C S S H$ for some fifty years at the time of his death on 25 August. He served the journal as author, editor, and long-term member of its various boards, but his presence was larger and his contributions to the quality of $\mathrm{CSSH}$ greater than mere titles can convey. His academic reputation grew from his extensive and challenging fieldwork among indigenous peoples, first of the Philippines and later of Australia. As an active scholar and faculty member, he remained a witty participant observer of academic departments and area centers at the University of Michigan and the University of California, Davis. Aram expressed his many passions in all aspects of his life, always attentive to Armenian culture and history, anthropological theory, nineteenth-century German thought, classical music, and American sports. He formed friendships that lasted a lifetime, from his days as a student at Fresno State, UCLA, and the University of Chicago and during his years as a professor at Michigan and Davis. Those friends now miss the stimulating vigor of his telephone calls.
\end{abstract}

